\title{
Coverage and determinants of influenza vaccine among pregnant women: a cross- sectional study
}

Vittoria Offeddu ${ }^{1 \dagger}$, Clarence C. Tam ${ }^{1,2+}$, Tze Tein Yong ${ }^{3}$, Lay Kok Tan ${ }^{3}$, Koh Cheng Thoon ${ }^{4}$, Nicole Lee ${ }^{4}$, Thiam Chye Tan ${ }^{4}$, George S. H. Yeo ${ }^{4}$ and Chee Fu Yung ${ }^{4,3^{*}}$

\begin{abstract}
Background: Pregnant women are at increased risk of influenza-related complications. The World Health Organisation recommends influenza vaccination to this high-risk population as highest priority. However, achieving high influenza vaccine coverage among pregnant women remains challenging. We conducted a cross-sectional survey to estimate the coverage and determinants of influenza vaccination among pregnant women in Singapore.

Methods: Between September and November 2017, pregnant women aged $\geq 21$ years were recruited at two public hospitals in Singapore. Participants completed an anonymous, self-administered online questionnaire assessing participants' influenza vaccination uptake, knowledge of and attitudes towards influenza and the influenza vaccine, vaccination history, willingness to pay for the influenza vaccine, and external cues to vaccination. We estimated vaccine coverage and used multivariable Poisson models to identify factors associated with vaccine uptake.

Results: Response rate was 61\% (500/814). Only 49 women (9.8, 95\% Confidence Interval (CI): 7.3-12.7\%) reported receiving the vaccine during their current pregnancy. A few misconceptions were identified among participants, such as the belief that influenza can be treated with antibiotics. The most frequent reason for not being vaccinated was lack of recommendation. Women who were personally advised to get vaccinated against influenza during pregnancy were 7 times more likely to be vaccinated (prevalence ratio (PR) $=7.11$; $95 \%$ Cl: 3.92-12.90). However, only $12 \%$ of women were personally advised to get vaccinated. Other factors associated with vaccine uptake were vaccination during a previous pregnancy ( $\mathrm{PR}=2.51 ; 95 \% \mathrm{Cl}: 1.54-4.11)$, having insurance to cover the cost of the vaccine $(\mathrm{PR}=2.32 ; 95 \% \mathrm{Cl}: 1.43-3.76)$, and higher vaccine confidence (PR $=1.62 ; 95 \% \mathrm{Cl}: 1.30-2.01)$.

Conclusions: Influenza vaccination uptake among pregnant women in Singapore is low. There is considerable scope for improving vaccination coverage in this high-risk population through vaccination recommendations from healthcare professionals, and public communication targeting common misconceptions about influenza and influenza vaccines.
\end{abstract}

Keywords: Influenza, Influenza vaccine, Maternal vaccination, Pregnancy, Vaccine recommendation

\footnotetext{
* Correspondence: yung.chee.fu@singhealth.com.sg

${ }^{\dagger}$ Vittoria Offeddu and Clarence C. Tam contributed equally to this work.

${ }^{4}$ KK Women's and Children's Hospital, Singapore 229899, Singapore

${ }^{5}$ Lee Kong Chian School of Medicine, NTU Imperial College, Singapore

636921, Singapore

Full list of author information is available at the end of the article
}

(c) The Author(s). 2019 Open Access This article is distributed under the terms of the Creative Commons Attribution 4.0 International License (http://creativecommons.org/licenses/by/4.0/), which permits unrestricted use, distribution, and reproduction in any medium, provided you give appropriate credit to the original author(s) and the source, provide a link to the Creative Commons license, and indicate if changes were made. The Creative Commons Public Domain Dedication waiver (http://creativecommons.org/publicdomain/zero/1.0/) applies to the data made available in this article, unless otherwise stated. 


\section{Background}

Pregnant women [1, 2] and new-borns [3-5] are at increased risk of complications from influenza infection. Immunisation with seasonal influenza vaccine during pregnancy is associated with lower incidence of influenza infection among pregnant women [6-10] and their new-borns up to six months of age [6-11].

In Singapore, influenza transmission occurs yearround, with two peaks of increased activity coinciding with the northern and southern hemisphere influenza seasons [12]. Since 2014, Singaporean residents in influenza high-risk groups can claim for the influenza vaccine using Medisave, a mandatory medical savings scheme [13]. Pregnant women of all gestational stages are recommended to get vaccinated against influenza [14, 15]. However, currently no data are available on influenza vaccine coverage among pregnant women. Coverage among other influenza high-risk groups, such as elderly [16] and children under five years [17], is low $(<15 \%)$.

This cross-sectional survey aimed to i) determine the level of influenza vaccine coverage among pregnant women in Singapore, ii) investigate pregnant women's knowledge, attitudes and practices towards influenza vaccination in the local context, and iii) identify factors associated with influenza vaccine uptake in this population. Our secondary objective was to compare uptake levels of influenza vaccine with coverage levels of other vaccines in the same population, including the tetanus, diphtheria, and pertussis vaccine, which is also recommended to pregnant women in Singapore, as well as the Hepatitis A and B and meningococcal vaccines.

\section{Methods}

\section{Recruitment}

Between September and November 2017, we recruited pregnant women attending Obstetrics and Gynaecology (OBGYN) clinics at KK Women's and Children Hospital $(\mathrm{KKH})$ and Singapore General Hospital (SGH) in Singapore. These two hospitals provide care for over a third of pregnancies in Singapore, and offer both public subsidised and private healthcare options. Trained data collectors were allocated to selected antenatal clinics at both hospitals. Apart from the inclusion of both private subsidised and private clinics, no other specific criteria were used for the clinic selection. Four data collectors visited the clinics at KKH on the two week days with the highest expected number of pre-natal appointments. On the remaining week days, recruitment was conducted at OBGYN clinics at SGH. Recruitment was suspended on days when other, unrelated activities were planned at the clinics. Data collectors approached all patients registering for an appointment in the clinic waiting room. Nonpregnant women and women younger than 21 years were excluded. Eligible individuals were asked to provide their informed consent through an online survey form. Consenting participants filled out an anonymous, selfadministered online questionnaire on an electronic tablet. Based on previous literature, we expected vaccination prevalence estimates in the range of 10 to $70 \%$. We estimated that a sample size of 500 participants was required to be able to estimate vaccine coverage values in this range with margins of error between \pm 2.5 and $\pm 4.5 \%$ at a confidence level of $95 \%$.

\section{Questionnaire}

Our conceptual framework was based on the Health Belief Model of health behaviour (Fig. 1) [18]. The questionnaire included domains assessing participants' demographics, vaccination history, knowledge, attitudes, insurance status, willingness to pay, cues to vaccination, and willingness to vaccinate (Additional file 1: Table S1).

Participants' knowledge level was assessed through 3 multiple-choice questions on influenza and 3 singlechoice questions on the influenza vaccine (Additional file 1: Table S2). Total knowledge score was calculated as the sum of individual question scores.

To assess participants' attitudes towards influenza and the use of influenza vaccine during pregnancy, respondents were asked to indicate their level of agreement with a series of statements on a 5-point scale.

Participants expressed their current willingness to get vaccinated during pregnancy on a 5-point likelihood scale. Subsequently, women were presented with 10 hypothetical scenarios and asked to indicate whether each of these scenarios would make them more or less likely than currently to be vaccinated during pregnancy. Overall willingness to vaccinate was calculated as the sum of willingness to vaccinate scores under all ten scenarios.

\section{Influenza vaccine uptake}

The main outcome of this study was self-reported influenza vaccination status during current pregnancy. We classified women who were unsure whether they had been vaccinated as unvaccinated, and estimated the proportion of vaccinated participants with 95\% exact binomial confidence intervals.

\section{Anchoring bias}

In order to detect potential anchoring bias, we created four different questionnaire forms. In one pair of forms, attitude questions on vaccine side effects were followed by questions on perceived vaccine effectiveness. In the willingness to vaccinate domain, negative scenarios were presented first. In a second pair of forms, the attitude domain asked questions on perceived vaccine effectiveness first, and negative scenarios were presented at the end of the willingness to vaccinate domain. Within each 


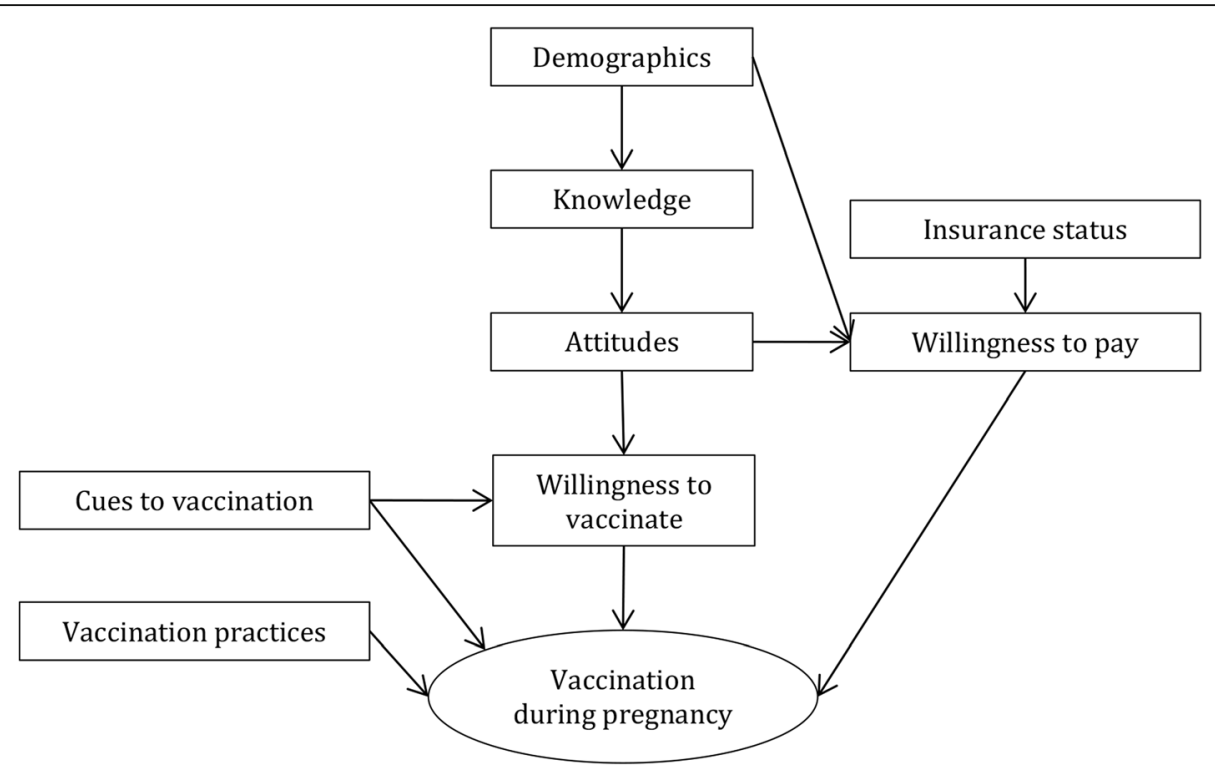

Fig. 1 Conceptual framework. Factors contributing to participants being vaccinated against influenza during current pregnancy; for variables under each domain, see Additional file 1 Tables S4 and S5

pair of forms, response options were ordered from most positive to most negative in one form, and in reverse order in the other. Upon consent, each participant was randomly directed to fill out one of the four different forms. We used $x^{2}$-tests to compare the distribution of responses to attitude and willingness to vaccinate questions across the different questionnaire forms.

\section{Factor analysis}

In order to define underlying attitudinal dimensions, we conducted exploratory factor analysis on the items in the attitudes domain using the iterated principal factor method. We examined polychoric correlation matrices [19] of items assessing respondents' attitudes and used the Kaiser-Meyer-Olkin test [20] of sampling adequacy to confirm that the data was suitable for factor analysis (threshold >0.7). We used parallel analysis and scree plot inflection points to determine the number of factors to be extracted. We used oblique promax rotation, and considered factor loadings $>0.3$ to be significant for inclusion of each item into a given factor. Factor scores were calculated using the regression-based method, and were standardized to a mean of zero and standard deviation of one. Predicted factor scores for individual participants were used as independent variables in multivariable regression analysis.

\section{Willingness to pay}

We used the Mann-Whitney U-test to compare median willingness to pay for one dose of influenza vaccine during pregnancy between vaccinated and unvaccinated individuals.

\section{Factors associated with influenza vaccination during pregnancy}

We identified predictors of influenza vaccination uptake during pregnancy through Poisson regression models with robust standard errors, using prevalence ratios (PRs) and related 95\% confidence intervals (CIs) as measures of association [21-23]. More details on the rationale for choosing these specific models can be found in the Supplementary Material for this manuscript.

In univariable analysis, we regressed each independent variable against the outcome and considered for inclusion in multivariable models those variables for which there was moderate to strong evidence for an association (Wald test $p$-value $<0.2$ ). We excluded three variables (Received information about the influenza vaccine from a polyclinic doctor, television, or newspapers), because the number of participants responding 'Yes' was very small $(<7)$ and none had been vaccinated, precluding estimation of a prevalence ratio. Since $95 \%$ of participants were married, marital status was excluded from this analysis. Being personally advised to get vaccinated during pregnancy was strongly associated with receiving information on the influenza vaccine (Pearson's $\chi^{2}: 256.5 ; p$-value $<0.001)$. Thus, the latter variable was excluded from the analysis.

Within each conceptual domain, we determined the set of independent variables most strongly associated with vaccination status by sequentially entering into the model candidate variables identified in the univariable analysis using a forward stepwise approach, starting with the most strongly associated variable. We retained variables with a Wald test $\mathrm{p}$-value $<0.1$. In the next 
stage, we sequentially entered the variables retained in different domains into the same multivariable regression model, retaining variables with a Wald test $\mathrm{p}$-value $<0.05$. Each variable initially excluded based on the results of univariable regression was again included into the final model to assess whether it would significantly contribute to it. No variable was reinserted into the final model based on this assessment.

All analyses were performed using Stata 14 (Stata Corporation).

\section{Ethics approval}

The study was approved by the SingHealth Centralised Institutional Review Board on August 8th, 2017 (reference number: 2017/2667).

\section{Results}

\section{Study population}

Of 883 women approached at the two study sites, two women aged $<21$ years and 67 non-pregnant individuals were excluded, leaving 814 (92\%) eligible women (Fig. 2). Of these, 552 (68\%) agreed to participate and 500 (61\%) submitted a completed questionnaire.

Most participants were Singaporean citizens (76\%) or permanent residents $(14 \%)$, and were predominantly of Chinese (40\%), Malay (33\%), or Indian (14\%) ethnicity (Table 1). Respondents were comparable to the national population of women giving birth to live children in the same time period in terms of age, although women of
Chinese ethnicity were under-represented and women of Malay ethnicity were over-represented in our sample. The majority of participants had a university degree (51\%) or post-secondary education (37\%) (Table 1).

\section{Influenza vaccine uptake}

Self-reported influenza vaccine uptake during the current pregnancy was 9.8\% (95\% CI: $7.3-12.7 \%)$ (Table 2). There was no significant difference in vaccine uptake by trimester (Table 2). In addition, 35.2\% (95\% CI: 31.0-39.6) of participants reported being vaccinated against influenza at least once outside of pregnancy. Twenty-nine out of 500 participants (6\%) were unsure whether they had been vaccinated against influenza during their current pregnancy and were classified as unvaccinated. Among 49 women vaccinated during their current pregnancy, about two thirds (63\%) were vaccinated at a hospital, while the remainder were vaccinated at a private general practice or polyclinic. The most common reasons to get vaccinated against influenza during pregnancy were recommendation by a healthcare worker (57\%), and protection from influenza in general (41\%) (Additional file 2: Figure S1-A).

Of 47 unvaccinated women in their first gestation trimester, 8 (17\%) intended to get vaccinated against influenza during their current pregnancy. The proportion of women in their second and third trimester planning to get vaccinated during their current pregnancy was 9 and 3\%, respectively. The main reasons not to get

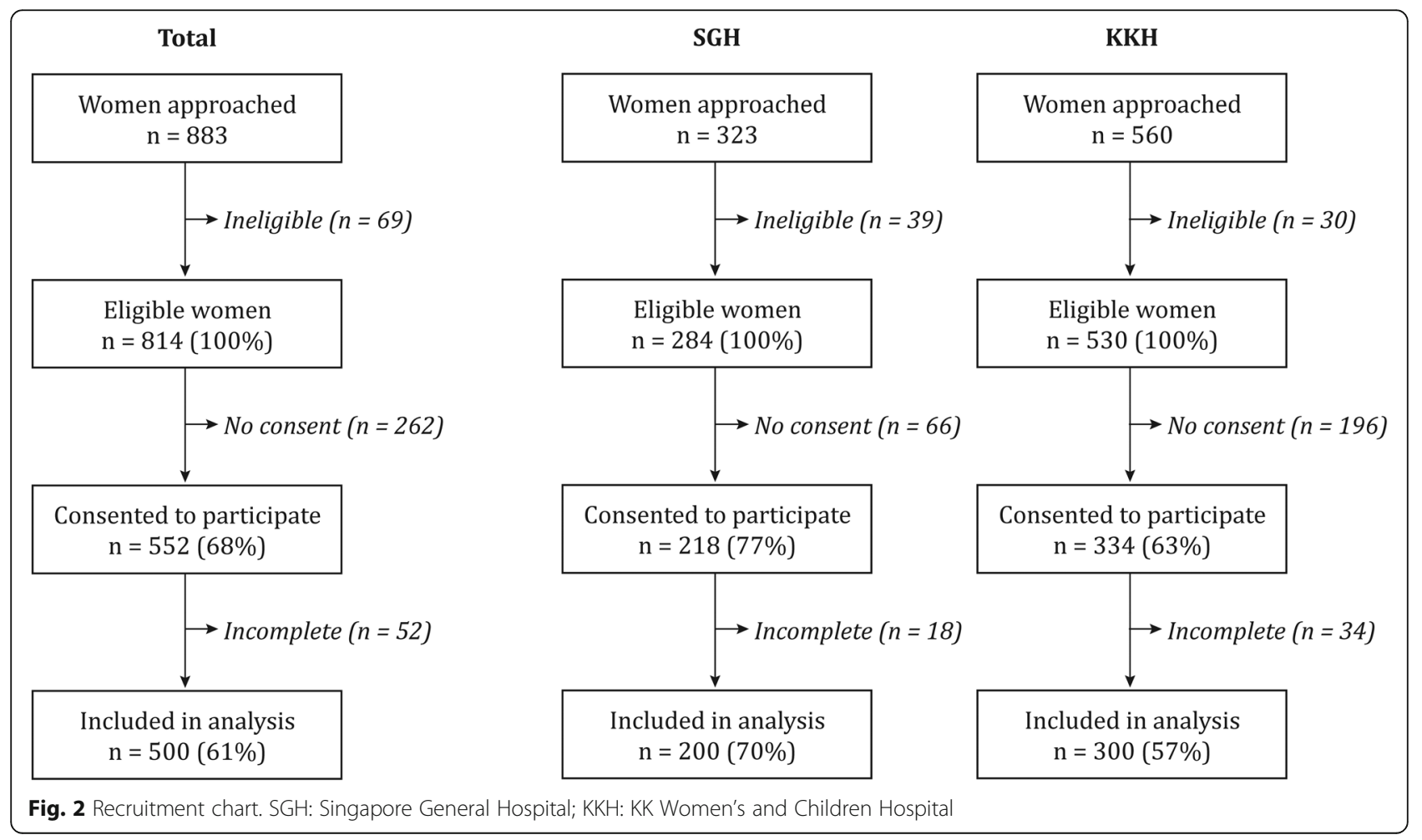


Table 1 Socio-demographic characteristics of study participants and comparison with women giving birth to live children among Singapore population in 2017

\begin{tabular}{|c|c|c|c|}
\hline & \multicolumn{2}{|c|}{ Study population } & \multirow{2}{*}{$\begin{array}{l}\text { National population }{ }^{a} \\
\%\end{array}$} \\
\hline & $\mathrm{n}$ & $\%$ & \\
\hline Total & 500 & 100 & 100 \\
\hline \multicolumn{4}{|l|}{ Age group (years) } \\
\hline 21 to 25 years & 54 & 10.8 & 5.0 \\
\hline 26 to 30 years & 184 & 36.8 & 26.1 \\
\hline 31 to 35 years & 182 & 36.4 & 40.9 \\
\hline 36 to 40 years & 71 & 14.2 & 22.7 \\
\hline 41 to 45 years & 9 & 1.8 & 4.4 \\
\hline \multicolumn{4}{|l|}{ Trimester of pregnancy } \\
\hline First (1 to 12 weeks) & 49 & 9.8 & \\
\hline Second (13 to 27 weeks) & 162 & 32.4 & \\
\hline Third (28 weeks and above) & 289 & 57.8 & \\
\hline \multicolumn{4}{|l|}{ Residential status } \\
\hline Citizen & 378 & 75.6 & \\
\hline Permanent Resident & 71 & 14.2 & \\
\hline Foreigner/ missing & 51 & 10.2 & \\
\hline \multicolumn{4}{|l|}{ Ethnic group } \\
\hline Chinese & 200 & 40.0 & 58.3 \\
\hline Malay & 163 & 32.6 & 20.1 \\
\hline Indian & 68 & 13.6 & 9.7 \\
\hline Other ${ }^{b}$ & 50 & 10.0 & 11.9 \\
\hline Prefer not to answer & 19 & 3.8 & \\
\hline \multicolumn{4}{|l|}{ Highest education level $^{\complement}$} \\
\hline Primary (PSLE or equivalent) & 2 & 0.4 & \\
\hline Lower secondary & 9 & 1.8 & \\
\hline Secondary (N/O levels pass) & 49 & 9.8 & \\
\hline Post-secondary (A levels/ Nitec/higher Nitec/Master Nitec) & 47 & 9.4 & \\
\hline Polytechnic & 68 & 13.6 & \\
\hline Professional qualification and other Diploma (NIE/TTE/SIM diploma) & 68 & 13.6 & \\
\hline University bachelor degree & 204 & 40.8 & \\
\hline University Master's degree and above & 53 & 10.6 & \\
\hline \multicolumn{4}{|l|}{ Total monthly household income } \\
\hline$<\$ 1000$ & 14 & 2.8 & \\
\hline$\$ 1000-\$ 4999$ & 213 & 42.6 & \\
\hline$\$ 5000-\$ 9999$ & 127 & 25.4 & \\
\hline$\$ 10,000-\$ 14,999$ & 48 & 9.6 & \\
\hline$\$ 15,000-\$ 19,999$ & 10 & 2.0 & \\
\hline$\$ 20,000+$ & 20 & 4.0 & \\
\hline Prefer not to answer & 68 & 13.6 & \\
\hline \multicolumn{4}{|l|}{ Type of housing } \\
\hline $\mathrm{HDB}^{\mathrm{d}} 1-2$ rooms & 21 & 4.2 & \\
\hline $\mathrm{HDB}^{\mathrm{d}} 3-4$ rooms & 274 & 54.8 & \\
\hline $\mathrm{HDB}^{\mathrm{d}} 5$ rooms & 112 & 22.4 & \\
\hline
\end{tabular}


Table 1 Socio-demographic characteristics of study participants and comparison with women giving birth to live children among Singapore population in 2017 (Continued)

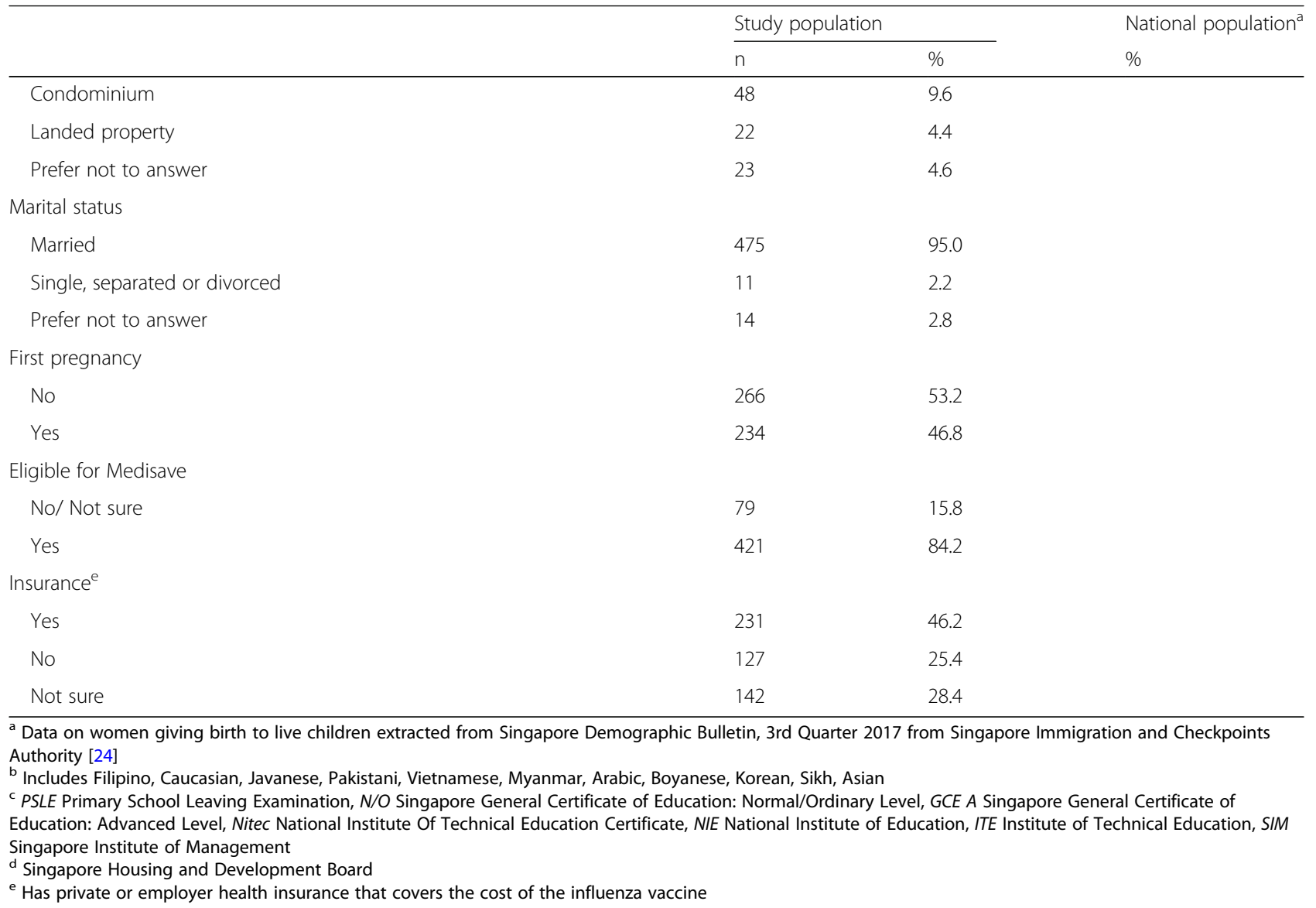

vaccinated included lack of recommendation (45\%) and lack of information on the influenza vaccine (31\%) (Additional file 2: Figure S1-B).

\section{Knowledge}

Most participants (90\%) identified viruses as the aetiological agent of influenza, although none recognised viruses as the sole cause. Overall, antibiotics were the most commonly selected option for influenza treatment (49\%). The majority of participants (77\%) were aware that there is an influenza vaccine. However, less than half $(46 \%)$ knew that influenza vaccination is recommended during pregnancy.

\section{Attitudes}

The majority of participants (>56\%) perceived themselves, their developing babies, and new-borns to be more vulnerable to severe influenza illness compared to other groups. Over half of all women (54\%) felt that vaccination during pregnancy was effective in protecting them against influenza illness, but only a third of them
(33\%) believed it would help protect their new-born. Nearly half of all women (46\%) felt more vulnerable to adverse events following vaccination during pregnancy, but only a small fraction of participants (21\%) were worried about potential side effects on their developing baby.

Exploratory factor analysis on items in the attitude domain revealed two latent dimensions, labelled as "Higher vaccine confidence" and "Higher perceived risk" (Additional file 1: Table S3). The correlation between the two dimensions was 0.156. Based on factor loadings, the dimension Higher vaccine confidence was highly correlated with higher perceived vulnerability to severe influenza illness during gestation, the belief that vaccination during pregnancy is safe and effective in protecting both pregnant women and their new-borns from severe influenza illness, and concern about side effects on the developing baby. The dimension Higher perceived risk was correlated with high perceived vulnerability to severe influenza illness among pregnant mothers, developing babies, and new-borns, and fear of side effects of 
Table 2 Self-reported influenza vaccine uptake during current pregnancy by demographic group

\begin{tabular}{|c|c|c|c|}
\hline \multirow[t]{2}{*}{ Total } & \multirow{2}{*}{$\begin{array}{l}\text { Total } n \\
500\end{array}$} & \multicolumn{2}{|c|}{$\%$ vaccinated $(95 \%$ C } \\
\hline & & 9.8 & $(7.3 ; 12.7)$ \\
\hline \multicolumn{4}{|l|}{ Age group (years) } \\
\hline 21 to 25 & 54 & 7.4 & $(2.1 ; 17.9)$ \\
\hline 26 to 30 & 184 & 14.7 & $(9.9 ; 20.6)$ \\
\hline 31 to 35 & 182 & 5.5 & $(2.7 ; 9.8)$ \\
\hline 36 to 46 & 80 & 10.0 & $(4.4 ; 18.8)$ \\
\hline \multicolumn{4}{|l|}{ Trimester } \\
\hline First ( 1 to 12 weeks) & 49 & 4.1 & $(0.5 ; 14.0)$ \\
\hline Second (13 to 27 weeks) & 162 & 11.7 & $(7.2 ; 17.7)$ \\
\hline Third ( 28 weeks and above) & 289 & 9.7 & $(6.5 ; 13.7)$ \\
\hline \multicolumn{4}{|l|}{ Residential status } \\
\hline Citizen & 378 & 9.3 & $(6.5 ; 12.6)$ \\
\hline Permanent resident & 71 & 11.3 & $(5.0 ; 21.0)$ \\
\hline Foreigner/missing & 51 & 11.8 & $(4.4 ; 23.9)$ \\
\hline \multicolumn{4}{|l|}{ Ethnicity } \\
\hline Chinese & 200 & 11.0 & $(7.0 ; 16.2)$ \\
\hline Malay & 163 & 6.1 & $(3.0 ; 11.0)$ \\
\hline Indian & 68 & 10.3 & $(4.2 ; 20.1)$ \\
\hline Other $^{\mathrm{a}}$ & 50 & 18.0 & $(8.6 ; 31.4)$ \\
\hline Prefer not to answer & 19 & 5.3 & $(0.1 ; 26.0)$ \\
\hline \multicolumn{4}{|l|}{ Education } \\
\hline Secondary and below & 60 & 3.3 & $(0.4 ; 11.5)$ \\
\hline Post-secondary & 183 & 6.0 & $(3.0 ; 10.5)$ \\
\hline University Bachelor degree & 204 & 13.2 & $(8.9 ; 18.7)$ \\
\hline University Masters degree and above & 53 & 17.0 & $(8.1 ; 29.8)$ \\
\hline \multicolumn{4}{|l|}{ Income } \\
\hline$<\$ 1000$ & 14 & 7.1 & $(0.1 ; 33.9)$ \\
\hline$\$ 1000-\$ 4999$ & 213 & 8.5 & $(5.1 ; 13.0)$ \\
\hline$\$ 5000-\$ 9999$ & 127 & 10.2 & $(5.6 ; 16.9)$ \\
\hline$\$ 10,000-\$ 14,999$ & 48 & 22.9 & $(12.0 ; 37.3)$ \\
\hline$\$ 15,000-\$ 19,999$ & 10 & 10.0 & $(0.3 ; 44.5)$ \\
\hline$\$ 20,000+$ & 20 & 10.0 & $(1.2 ; 31.7)$ \\
\hline Prefer not to answer & 68 & 4.4 & $(0.9 ; 12.4)$ \\
\hline \multicolumn{4}{|l|}{ Housing } \\
\hline $\mathrm{HDB}^{\mathrm{b}} 1-2$ rooms & 21 & 4.8 & $(0.1 ; 23.8)$ \\
\hline $\mathrm{HDB}^{\mathrm{b}} 3-4$ rooms & 274 & 6.6 & $(0.4 ; 10.2)$ \\
\hline $\mathrm{HDB}^{\mathrm{b}} 5$ rooms & 112 & 11.6 & $(6.3 ; 19.0)$ \\
\hline Condo & 48 & 12.5 & $(4.7 ; 25.2)$ \\
\hline Landed property & 22 & 45.5 & $(24.4 ; 67.8)$ \\
\hline Prefer not to answer & 23 & 4.3 & $(0.1 ; 21.9)$ \\
\hline \multicolumn{4}{|l|}{ Marital status } \\
\hline Married & 475 & 9.3 & $(6.8 ; 12.2)$ \\
\hline Single/separated/ divorced & 11 & 36.4 & $(10.9 ; 69.2)$ \\
\hline
\end{tabular}

Table 2 Self-reported influenza vaccine uptake during current pregnancy by demographic group (Continued)

\begin{tabular}{llll}
\hline Total & Total $\mathrm{n}$ & \multicolumn{2}{c}{$\%$ vaccinated $(95 \% \mathrm{Cl})$} \\
\cline { 4 - 4 } & 500 & 9.8 & $(7.3 ; 12.7)$ \\
\hline Prefer not to answer & 14 & 7.1 & $(0.1 ; 33.9)$ \\
First pregnancy & & & \\
$\quad$ No & 266 & 9.0 & $(5.9 ; 13.1)$ \\
$\quad$ Yes & 234 & 10.7 & $(7.0 ; 15.4)$ \\
Eligible for Medisave & & & \\
$\quad$ No/ Not sure & 79 & 8.9 & $(3.6 ; 17.4)$ \\
$\quad$ Yes & 421 & 10.0 & $(7.3 ; 13.2)$ \\
Insurance & & & \\
$\quad$ No & 231 & 6.5 & $(3.7 ; 10.5)$ \\
$\quad$ Yes & 127 & 22.1 & $(15.2 ; 30.3)$ \\
Not sure & 142 & 4.2 & $(1.6 ; 9.0)$ \\
\hline
\end{tabular}

a Includes Filipino, Caucasian, Javanese, Pakistani, Vietnamese, Myanmar, Arabic, Boyanese, Korean, Sikh, Asian

${ }^{\mathrm{b}}$ Singapore Housing and Development Board

c Has private or employer health insurance that covers the cost of the influenza vaccine

vaccination on both mother and developing baby. These two factors explained $83 \%$ of total variance in the attitudes data.

\section{Willingness to vaccinate}

Overall, willingness to vaccinate against influenza was low (Fig. 3). Nearly half of unvaccinated women (48\%) stated they were unlikely or very unlikely to get vaccinated during current gestation, and an additional 39\% felt neutral about vaccination during pregnancy. A fraction of participants (14\%) stated their willingness to vaccinate would not increase under any of the hypothetical scenarios presented. However, almost two thirds of women $(>60 \%)$ stated their willingness to vaccinate would increase if they knew that vaccination during pregnancy can protect them or their new-born from severe influenza illness. Other factors increasing participants' willingness to vaccinate included recommendations from an obstetrician or the Ministry of Health, and free vaccination. Conversely, participants' willingness to vaccinate was only moderately affected by recommendation from a pharmacist or a nurse (Fig. 3).

\section{Anchoring bias}

There were no significant differences in the distribution of responses to questions across the four different questionnaire forms, indicating a negligible effect of question order or response option order on participants' responses to either attitudes or willingness to vaccinate questions. 


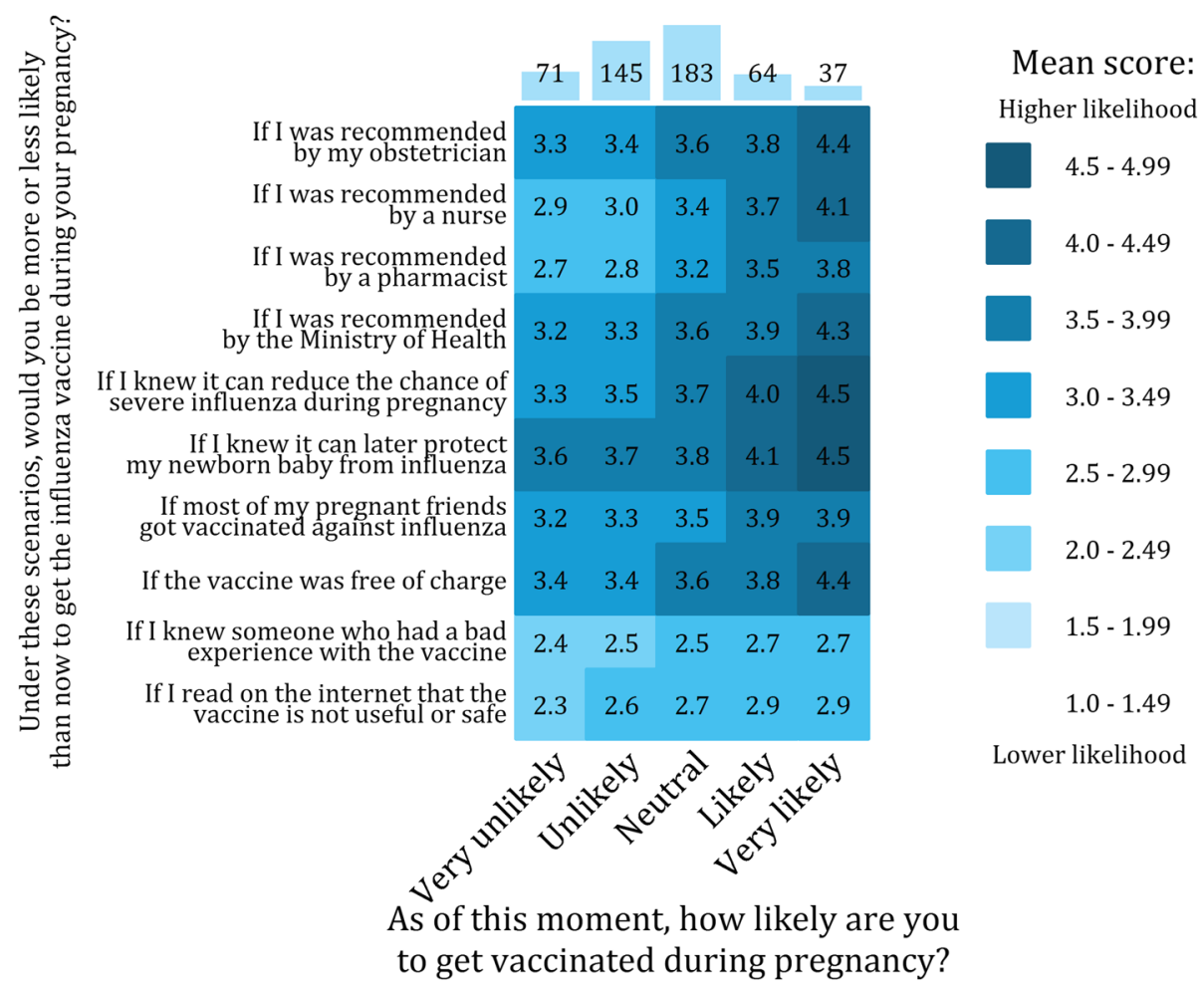

Fig. 3 Willingness to vaccinate. Willingness to vaccinate under different scenarios ( $x$-axis), by current willingness to vaccinate during pregnancy (y-axis). Darker colours indicate greater willingness than currently to vaccinate against influenza during pregnancy under the scenarios presented. Numbers in boxes represent respondent mean scores on a 5 -point scale ( $1=$ Very unlikely; $2=$ Unlikely; $3=$ Neutral; $4=$ Likely; $5=$ Very likely). The bar chart on the right denotes the distribution of respondents by category of current willingness to vaccinate

\section{Cues to vaccination}

Among participants, $17 \%$ had received information about the influenza vaccine during their current pregnancy. The most common sources of information for these participants were friends, family or employers (37\%), although women most commonly indicated their obstetrician (71\%) and official websites (40\%), such as the Ministry of Health or Health Promotion Board websites, as their preferred sources of information.

Only $12 \%$ of respondents had been personally advised to get vaccinated. Of these, $34 \%$ were recommended by their obstetrician, while others were advised by their general practitioner $(22 \%)$, a nurse $(22 \%)$, or friends and family (21\%).

\section{Willingness to pay}

Out of 421 participants eligible for Medisave, 34 (8\%) stated they would not pay any amount for one dose of influenza vaccine during pregnancy. Among those willing to pay, median willingness to pay for one dose out of Medisave was SGD50 ( USD37) (range: 1-600 SGD/ 1-440 USD; interquartile range: SGD50-100/ USD37-74). This was higher than the price of the vaccine in most clinics and general practices in Singapore, and higher than median willingness to pay among parents of children in the age groups recommended for vaccination [17]. There was no significant difference in median willingness to pay out of Medisave between vaccinated and unvaccinated women (SGD60 vs SGD50, MannWhitney $\mathrm{U}$ test: $p$-value $=0.9)$.

\section{Factors associated with influenza vaccination}

Results from univariable analysis are reported in Additional file 1: Tables S4 and S5. In the final multivariable analysis, women who were personally advised to receive the influenza vaccine during pregnancy were seven times more likely to be vaccinated compared to women who were not recommended vaccination $(\mathrm{PR}=7.11$; 95\% CI: 3.92-12.90) (Table 3). Other variables independently associated with higher vaccination uptake included vaccination during a previous pregnancy $(\mathrm{PR}=2.51 ; 95 \% \mathrm{CI}: 1.54-4.11)$, and having private or employer health insurance that covers the cost of the vaccine ( $\mathrm{PR}=2.32 ; 95 \% \mathrm{CI}: 1.43-3.76$ ). There was a linear association between vaccination uptake and the Higher vaccine confidence factor, with 
Table 3 Multivariable analysis of factors associated with reported influenza vaccination uptake during current pregnancy

\begin{tabular}{|c|c|c|c|}
\hline & \multicolumn{3}{|c|}{ Multivariable analysis } \\
\hline & Adjusted PR ${ }^{a}$ & $95 \% \mathrm{Cl}$ & $P$-value \\
\hline \multicolumn{4}{|l|}{ Cues to vaccination } \\
\hline $\begin{array}{l}\text { Was personally advised to get vaccinated } \\
\text { against influenza during current pregnancy }\end{array}$ & & & $<0.001$ \\
\hline No & 1 & & \\
\hline Yes & 7.11 & $3.92 ; 12.90$ & \\
\hline Not sure & 1.98 & $0.71 ; 5.49$ & \\
\hline \multicolumn{4}{|l|}{ Vaccination practices } \\
\hline \multicolumn{4}{|l|}{$\begin{array}{l}\text { Was vaccinated against influenza during } \\
\text { previous pregnancy }\end{array}$} \\
\hline $\mathrm{No}^{\mathrm{b}}$ & 1 & & \\
\hline Yes & 2.51 & $1.54 ; 4.11$ & $<0.001$ \\
\hline Insurance status & & & 0.001 \\
\hline Not insured & 1 & & \\
\hline Insured & 2.32 & $1.43 ; 3.76$ & \\
\hline Not sure & 1.03 & $0.46 ; 2.26$ & \\
\hline Higher vaccine confidence (Factor 1$)^{c, d}$ & $1.62^{c}$ & $1.30 ; 2.01$ & $<0.001$ \\
\hline Willingness to vaccinate ${ }^{c}$ & 1.06 & $1.01 ; 1.12$ & 0.011 \\
\hline
\end{tabular}

a $62 \%$ increase in vaccination prevalence per 1 standard deviation increase in the score for this factor (PR $=1.62 ; 95 \%$ CI: 1.30-2.01) (Table 3).

\section{Other vaccines}

Few participants reported receiving the tetanus $(2 \%)$ or combined tetanus-diphtheria-pertussis vaccine (3\%) during pregnancy. Uptake of vaccination against Hepatitis $\mathrm{A}$ and $B$ was 2 and $6 \%$, respectively, while $<1 \%$ of participants reported receiving meningococcal vaccination.

\section{Discussion}

\section{Main findings}

In this survey, we assessed the uptake and determinants of influenza vaccination among pregnant women in Singapore. Although most participants were knowledgeable about influenza, a few common misconceptions were identified, such as the belief that influenza can be treated with antibiotics. Although awareness of the influenza vaccine was high, and the majority of women had a positive attitude towards vaccination during pregnancy, willingness to vaccinate was low. Only $10 \%$ of participants reported being vaccinated against influenza during their current gestation. Being personally advised to get vaccinated during pregnancy was the most significant factor associated with increased vaccination uptake, but only a small proportion of women were personally advised to get vaccinated.

Studies from other Southeast Asian countries reported equally low $(<10 \%)$ influenza vaccine uptake [25-28]. In Hong Kong, women were six times more likely to get vaccinated during pregnancy if recommended by a healthcare professional $[26,27]$. Similarly, recommendation from a healthcare provider was associated with higher willingness to vaccinate among pregnant women in Thailand [28]. Even in countries where influenza vaccine uptake among pregnant women is comparatively high, recommendation from healthcare professionals was consistently one of the most important factors increasing vaccination uptake [29-31]. In our study, women who were personally advised to be vaccinated against influenza during pregnancy were seven times more likely to take up the vaccine. However, only a few pregnant women were personally advised or informed about the influenza vaccine, and less than half of participants were aware of existing recommendations. In some settings, pharmacist-led provision of influenza vaccines is well accepted [32, 33], and contributes to increased vaccine uptake [33-35]. However, participants' willingness to vaccinate was only moderately affected by recommendation from a pharmacist in our study. This finding highlights the importance of investigating factors 
which may affect the effectiveness of maternal vaccination strategies in different cultural contexts.

Healthcare providers who are more knowledgeable $[36,37]$ and confident $[38,39]$ about the influenza vaccine are more likely to recommend vaccination and obtain high coverage among expecting mothers. In Singapore, qualitative studies have revealed limited influenza vaccine acceptance among healthcare professionals [40, 41]. Provider-targeted interventions involving education, automatic reminders, and vaccination training effectively increased vaccination uptake among pregnant patients in other settings [42], and may be key to increasing uptake among pregnant women and other high-risk groups [17] in Singapore. Lack of incentives and financial barriers, including the cost of ordering and stocking the vaccine, may also influence healthcare providers' practices $[43,44]$.

Consistent with previous findings [27, 31, 36, 45-47], we found that greater concern about influenza illness coupled with greater confidence in influenza vaccine were associated with increased vaccination uptake during pregnancy. In contrast, greater perceived risk of influenza severity and vaccine side effects did not significantly affect vaccination uptake in this population. In contrast, concerns about vaccine side effects have been found to be negatively associated with vaccine uptake during pregnancy in other settings $[46,48]$.

Among our study participants, lack of information on the influenza vaccine was one of the most common reasons not to get vaccinated. This was in agreement with a recent survey among parents of young children in Singapore, where those who felt well-informed were more likely to have vaccinated their child in the past [17]. Patient-targeted educational interventions are moderately effective in increasing influenza vaccine uptake [42], but may help in curbing common misconceptions, such as the belief that influenza can be treated with antibiotics.

\section{Limitations}

Our study sample only included participants from public hospitals, and may not have been representative of all pregnant women in Singapore. However, both hospitals catered to patients receiving public and private healthcare. Furthermore, both hospitals are responsible for antenatal care covering more than a third of the annual birth cohort in Singapore. Women who got vaccinated against influenza during their pregnancy may have been more likely to participate in this survey, resulting in an overestimation of vaccine coverage. Given the low reported uptake, this potential bias may be negligible. If participants who were planning to get vaccinated against influenza at the time of the survey actually did so at a later stage of their pregnancy, our survey may have underestimated vaccine coverage in this population. However, there was no evidence of increasing uptake by trimester of pregnancy. Vaccination status was selfreported and thus potentially subject to poor recall. Currently, there is no adult immunization registry in Singapore, and our survey was anonymous so we did not have access to medical records to validate self-reported vaccination status. However, previous studies have shown that self-reported influenza vaccination uptake overestimates coverage as reported in computerized vaccination registries [49]. In our study, $<6 \%$ of women were unsure of their influenza vaccination status. Assuming all these women were in fact vaccinated, though unrealistic, would still only increase coverage to about $16 \%$. Given that personal recommendation was the key factor associated with vaccination, and that pregnant women tend to be more aware of their health and well-being, we expect that women who were vaccinated during their current pregnancy would have been likely to remember it. Excluding those who were unsure whether they had been vaccinated during current pregnancy from the multivariable analysis did not alter the results (data not shown). A number of vaccines are recommended during pregnancy, and respondents may not have been able to reliably distinguish between these. However, reported vaccination during pregnancy was low for all vaccines and influenza vaccine was the most commonly reported. Since the survey was anonymous, it was not possible to ensure that the same woman did not participate on more than one occasion. However, no remuneration was given to participants for taking part in this survey, limiting the incentive for women to participate more than once. In addition, the survey was conducted within a time span of less than two months, so that a woman would likely remember if she had taken part in the survey before. Finally, the low number of vaccinated individuals may have limited study power to detect additional factors associated with vaccination.

\section{Conclusions}

Coverage of influenza vaccine among pregnant women is low in Singapore. Encouraging healthcare professionals, especially obstetricians, to recommend influenza vaccination is key to improving vaccine uptake in this population. In contrast to other settings, the potential impact of pharmacy-led maternal influenza vaccination strategies may be limited in Singapore. Public communication about influenza vaccination should target common misconceptions about influenza and influenza vaccines. The baseline data collected in this survey can be used to measure the impact of future interventions on influenza vaccine coverage among pregnant women. With the recent inclusion of maternal pertussis vaccination into the pregnancy immunisation schedule and 
progress towards novel respiratory syncytial virus vaccines, the repertoire of vaccines recommended in pregnancy is likely to increase. Our findings provide additional insights for public health authorities to plan and implement targeted strategies to improve coverage of maternal vaccinations.

\section{Additional files}

Additional file 1: Table S1. Details of survey questionnaire. Table S2. Scoring of knowledge questions. Table S3. Exploratory factor analysis. Table S4. Univariable analysis of socio-demographic variables, practices, and cues to vaccination. Table S5. Univariable analysis of knowledge, attitude, and willingness to vaccinate variables (DOCX $290 \mathrm{~kb}$ )

Additional file 2: Figure S1. Figure showing reasons for taking and not taking influenza vaccine during current pregnancy among study participants. (TIFF $5357 \mathrm{~kb}$ )

\section{Abbreviations}

95\% Cl: 95\% Confidence Interval; GCE A: Singapore General Certificate of Education: Advanced Level; GCE N/O: Singapore General Certificate of Education: Normal/Ordinary Level; HDB: Singapore Housing and Development Board; ITE: Institute of Technical Education; KKH: KK Women's and Children Hospital Singapore; NIE: National Institute of Education; Nitec: National Institute of Technical Education Certificate; OBGYN: Obstetrics and Gynaecology; PR: Prevalence Ratio; PSLE: Primary School Leaving Examination; SGD: Singapore Dollar; SGH: Singapore General Hospital; SIM: Singapore Institute of Management; USD: United States Dollar

\section{Acknowledgements}

We would like to thank Yu Chun Yan, Zhou Xiuqing and all other nurses at the Obstetrics and Gynaecology clinics at Singapore General Hospital and KK Women's and Children's Hospital for their support in facilitating data collection. In addition, we would like to thank Nur Sarah Bte Johari, Foo Zhi Yao Mark, Gayathiri D/O Sivakumar G, and Lim Yi Hui Valencia for collecting the data. We would also like to thank all the pregnant women who agreed to complete the survey.

\section{Authors' contributions}

All authors attest they meet the ICMJE criteria for authorship. CFY conceived the idea for this study, provided input for data collection and analysis and drafting the manuscript. CCT and VO collected the data, conducted the analysis, and wrote the manuscript. VO, CCT, TTY, LKT, KCT, NL, TCT, GSHY, and CFY contributed to critically revise the manuscript. All authors read and approved the final manuscript.

\section{Funding}

This research did not receive any specific grant from funding agencies in the public, commercial, or not-for-profit sectors.

\section{Availability of data and materials}

The datasets used and/or analysed during the current study are available from the corresponding author on reasonable request.

\section{Ethics approval and consent to participate}

The study was approved by the SingHealth Centralised Institutional Review Board on August 8th, 2017 (reference number: 2017/2667). Documented, signed informed consent was not deemed necessary for this anonymous survey. Eligible individuals were asked to provide their informed consent by checking a box on the online survey form before starting the survey.

\section{Consent for publication}

Not applicable.

\section{Competing interests}

The authors declare that they have no competing interests.

\section{Author details}

Saw Swee Hock School of Public Health, National University of Singapore and National University Health System, Singapore 117549, Singapore. ${ }^{2}$ London School of Hygiene \& Tropical Medicine, London WC1E 7HT, UK. ${ }^{3}$ Singapore General Hospital, Singapore 169608, Singapore. ${ }^{4}$ KK Women's and Children's Hospital, Singapore 229899, Singapore. ${ }^{5}$ Lee Kong Chian School of Medicine, NTU Imperial College, Singapore 636921, Singapore.

Received: 6 October 2018 Accepted: 17 June 2019

Published online: 05 July 2019

\section{References}

1. Mertz D, Geraci J, Winkup J, Gessner BD, Ortiz JR, Loeb M. Pregnancy as a risk factor for severe outcomes from influenza virus infection: a systematic review and meta-analysis of observational studies. Vaccine. 2017:35:521-8. https://doi.org/10.1016/j.vaccine.2016.12.012.

2. Katz MA, Gessner BD, Johnson J, Skidmore B, Knight M, Bhat N, et al. Incidence of influenza virus infection among pregnant women: a systematic review. BMC Pregnancy Childbirth. 2017;17:155. https://doi.org/10.1186/ s12884-017-1333-5.

3. Fell DB, Johnson J, Mor Z, Katz MA, Skidmore B, Neuzil KM, et al. Incidence of laboratory-confirmed influenza disease among infants under 6 months of age: a systematic review. BMJ Open. 2017;7:e016526. https://doi.org/10. 1136/bmjopen-2017-016526.

4. Poehling KA, Edwards KM, Griffin MR, Szilagyi PG, Staat MA, Iwane MK, et al. The burden of influenza in young children, 2004-2009. Pediatrics. 2013;131: 207-16. https://doi.org/10.1542/peds.2012-1255.

5. Ang LW, Lim C, Lee VJM, Ma S, Tiong WW, Ooi PL, et al. Influenza-associated hospitalizations, Singapore, 2004-2008 and 2010-2012. Emerg Infect Dis. 2014;20:1652-60. https://doi.org/10.3201/eid2010.131768.

6. Tapia MD, Sow SO, Tamboura B, Tégueté I, Pasetti MF, Kodio M, et al. Maternal immunisation with trivalent inactivated influenza vaccine for prevention of influenza in infants in Mali: a prospective, active-controlled, observer-blind, randomised phase 4 trial. Lancet Infect Dis. 2016;16:1026-35 https://doi.org/10.1016/S1473-3099(16)30054-8.

7. Madhi SA, Cutland CL, Kuwanda L, Weinberg A, Hugo A, Jones S, et al. Influenza vaccination of pregnant women and protection of their infants. N Engl J Med. 2014;371:918-31. https://doi.org/10.1056/NEJMoa1401480.

8. Steinhoff MC, Katz J, Englund JA, Khatry SK, Shrestha L, Kuypers J, et al. Yearround influenza immunisation during pregnancy in Nepal: a phase 4, randomised, placebo-controlled trial. Lancet Infect Dis. 2017;17:981-9. https://doi.org/10.1016/S1473-3099(17)30252-9.

9. Zaman K, Roy E, Arifeen SE, Rahman M, Raqib R, Wilson E, et al. Effectiveness of maternal influenza immunization in mothers and infants. N Engl J Med. 2008;359:1555-64. https://doi.org/10.1056/NEJMoa0708630.

10. Steinhoff MC, Omer SB, Roy E, El Arifeen S, Ragib R, Dodd C, et al. Neonatal outcomes after influenza immunization during pregnancy: a randomized controlled trial. Cmaj. 2012;184:645-53. https://doi.org/10.1503/cmaj.110754.

11. Nunes MC, Madhi SA. Prevention of influenza-related illness in young infants by maternal vaccination during pregnancy. F1000Research. 2018;7: 122. https://doi.org/10.12688/f1000research.12473.1.

12. Ang LW, Tien WS, Lin RT-P, Cui L, Cutter J, James L, et al. Characterization of influenza activity based on virological surveillance of influenza-like illness in tropical Singapore, 2010-2014. J Med Virol. 2016;88:2069-77. https://doi.org/ 10.1002/jmv.24566.

13. Singapore Ministry of Health. Medisave uses and withdrawal limits. 2017. https://www.moh.gov.sg/content/moh_web/home/costs_and_ financing/schemes_subsidies/medisave/Withdrawal_Limits.html. Accessed 25 Apr 2018.

14. Singapore Ministry of Health. $\mathrm{MOH}$ establishes national adult immunisation schedule; extends use of medisave for vaccines under the schedule. 2017. https://www.moh.gov.sg/content/moh_web/home/pressRoom/ pressRoomltemRelease/2017/moh-establishes-national-adult-immunisationschedule\%2D\%2Dextends-us.html. Accessed 25 Apr 2018.

15. World Health Organization. Vaccines against influenza. WHO position paper November. 2012. http://www.who.int/immunization/position_papers/PP influenza_november2012_summary.pdf. Accessed 25 Apr 2018.

16. Ang LW, Cutter J, James L, Goh KT. Factors associated with influenza vaccine uptake in older adults living in the community in Singapore. Epidemiol Infect. 2017:145:775-86. https://doi.org/10.1017/ S0950268816002491. 
17. Low MSF, Tan H, Hartman M, Tam CC, Hoo C, Lim J, et al. Parental perceptions of childhood seasonal influenza vaccination in Singapore: a cross-sectional survey. Vaccine. 2017;35:6096-102. https://doi.org/10.1016/j. vaccine.2017.09.060

18. Rosenstock IM. Historical origins of the health belief model. Heal Educ Behav. 1974;2:328-5e.

19. Holgado-Tello FP, Chacón-Moscoso S, Barbero-García I, Vila-Abad E. Polychoric versus Pearson correlations in exploratory and confirmatory factor analysis of ordinal variables. Qual Quant. 2010;44:153-66. https://doi. org/10.1007/s11135-008-9190-y.

20. Cerny BA, Kaiser HF. A study of a measure of sampling adequacy for factoranalytic correlation matrices. Multivariate Behav Res. 1977;12:43-7. https:// doi.org/10.1207/s15327906mbr1201_3.

21. Barros AJD, Hirakata VN. Alternatives for logistic regression in cross-sectional studies: an empirical comparison of models that directly estimate the prevalence ratio. BMC Med Res Methodol. 2003;3:21. https://doi.org/10.1186/ 1471-2288-3-21.

22. Deddens JA, Petersen MR. Approaches for estimating prevalence ratios. Occup Environ Med. 2008;65:501-6. https://doi.org/10.1136/ oem.2007.034777.

23. Zou G. A modified poisson regression approach to prospective studies with binary data. Am J Epidemiol. 2004;159:702-6 http://www.ncbi.nlm.nih.gov/ pubmed/15033648. Accessed 13 Feb 2019.

24. Singapore Immigration and Checkpoints Authority. Singapore demographic bulletin, 1st quarter. 2018. https://www.ica.gov.sg/stats. Accessed 21 May 2018

25. Owusu JT, Prapasiri $P$, Ditsungnoen $D$, Leetongin $G$, Yoocharoen $P$, Rattanayot J, et al. Seasonal influenza vaccine coverage among high-risk populations in Thailand, 2010-2012. Vaccine. 2015;33:742-7. https://doi.org/ 10.1016/j.vaccine.2014.10.029.

26. Lau JTF, Cai Y, Tsui HY, Choi KC. Prevalence of influenza vaccination and associated factors among pregnant women in Hong Kong. Vaccine. 2010;28: 5389-97. https://doi.org/10.1016/j.vaccine.2010.05.071.

27. Yuet Sheung Yuen C, Yee Tak Fong D, Lai Yin Lee I, Chu S, Sau-mei Siu E, Tarrant M. Prevalence and predictors of maternal seasonal influenza vaccination in Hong Kong. Vaccine. 2013;31:5281-8. https://doi.org/10.1016/ j.vaccine.2013.08.063.

28. Ditsungnoen D, Greenbaum A, Praphasiri P, Dawood FS, Thompson MG, Yoocharoen $\mathrm{P}$, et al. Knowledge, attitudes and beliefs related to seasonal influenza vaccine among pregnant women in Thailand. Vaccine. 2016;34: 2141-6. https://doi.org/10.1016/j.vaccine.2016.01.056.

29. Yuen CYS, Tarrant M. Determinants of uptake of influenza vaccination among pregnant women - a systematic review. Vaccine. 2014;32:4602-13. https://doi.org/10.1016/j.vaccine.2014.06.067.

30. Bödeker B, Walter D, Reiter S, Wichmann O. Cross-sectional study on factors associated with influenza vaccine uptake and pertussis vaccination status among pregnant women in Germany. Vaccine. 2014;32:4131-9. https://doi. org/10.1016/j.vaccine.2014.06.007.

31. Henninger ML, Irving SA, Thompson M, Avalos LA, Ball SW, Shifflett $P$, et al Factors associated with seasonal influenza vaccination in pregnant women. J Women's Heal. 2015;24:394-402. https://doi.org/10.1089/jwh.2014.5105.

32. Bach AT, Goad JA. The role of community pharmacy-based vaccination in the USA: current practice and future directions. Integr Pharm Res Pract. 2015;4:67-77. https://doi.org/10.2147/IPRP.S63822.

33. Warner JG, Portlock J, Smith J, Rutter P. Increasing seasonal influenza vaccination uptake using community pharmacies: experience from the Isle of Wight, England. Int J Pharm Pract. 2013;21:362-7. https://doi.org/10.1111/ ijpp.12037.

34. Steyer TE, Ragucci KR, Pearson WS, Mainous AG. The role of pharmacists in the delivery of influenza vaccinations. Vaccine. 2004;22:1001-6. https://doi. org/10.1016/j.vaccine.2003.08.045.

35. Drozd E, Miller L, Johnsrud M. Impact of pharmacist immunization Authority on seasonal influenza immunization rates across states. Clin Ther. 2017;39: 1563-80.

36. Tong A, Biringer A, Ofner-Agostini M, Upshur R, McGeer A. A cross-sectional study of maternity care providers' and women's knowledge, attitudes, and behaviours towards influenza vaccination during pregnancy. J Obstet Gynaecol Can. 2008;30:404-10 http://www.ncbi.nlm.nih.gov/pubmed/ 18505664. Accessed 21 May 2018.

37. Eppes C, Wu A, Cameron KA, Garcia P, Grobman W. Does obstetrician knowledge regarding influenza increase HINI vaccine acceptance among their pregnant patients? Vaccine. 2012;30:5782-4. https://doi.org/10.1016/j. vaccine.2012.06.032

38. Praphasiri P, Ditsungneon D, Greenbaum A, Dawood FS, Yoocharoen P, Stone DM, et al. Do Thai physicians recommend seasonal influenza vaccines to pregnant women? A cross-sectional survey of physicians' perspectives and practices in Thailand. PLoS One. 2017;12:e0169221. https://doi.org/10. 1371/journal.pone.0169221.

39. Maher L, Dawson A, Wiley K, Hope K, Torvaldsen S, Lawrence G, et al. Influenza vaccination during pregnancy: a qualitative study of the knowledge, attitudes, beliefs, and practices of general practitioners in central and South-Western Sydney. BMC Fam Pract. 2014;15:102. https://doi. org/10.1186/1471-2296-15-102.

40. Sundaram N, Duckett K, Yung CF, Thoon KC, Sidharta S, Venkatachalam I, et al. "I wouldn't really believe statistics"; - Challenges with influenza vaccine acceptance among healthcare workers in Singapore. Vaccine. 2018;36:19962004. https://doi.org/10.1016/j.vaccine.2018.02.102.

41. Hwang SW, Lim HB. Barriers and motivators of influenza vaccination uptake among primary healthcare Workers in Singapore. Proc Singapore Healthc. 2014;23:126-33.

42. Wong WY, Lok KYW, Tarrant M. Interventions to increase the uptake of seasonal influenza vaccination among pregnant women: a systematic review. Vaccine. 2016;34:20-32. https://doi.org/10.1016/j.vaccine.2015.11.020.

43. Power ML, Leddy MA, Anderson BL, Gall SA, Gonik B, Schulkin J. Obstetrician-gynecologists' practices and perceived knowledge regarding immunization. Am J Prev Med. 2009;37:231-4. https://doi.org/10.1016/j. amepre.2009.05.019.

44. Shavell VI, Moniz MH, Gonik B, Beigi RH. Influenza immunization in pregnancy: overcoming patient and health care provider barriers. Am J Obstet Gynecol. 2012;207(3 Suppl):S67-74. https://doi.org/10.1016/j.ajog. 2012.06.077.

45. Gorman JR, Brewer NT, Wang JB, Chambers CD. Theory-based predictors of influenza vaccination among pregnant women. Vaccine. 2012;31:213-8. https://doi.org/10.1016/j.vaccine.2012.10.064

46. Wiley KE, Massey PD, Cooper SC, Wood NJ, Ho J, Quinn HE, et al. Uptake of influenza vaccine by pregnant women: a cross-sectional survey. Med J Aust. 2013;198:373-5. https://doi.org/10.5694/mja12.11849.

47. Kang HS, De Gagne JC, Kim J-H. Attitudes, intentions, and barriers toward influenza vaccination among pregnant Korean women. Health Care Women Int. 2015;36:1026-38. https://doi.org/10.1080/07399332.2014.942903.

48. Henninger M, Naleway A, Crane B, Donahue J, Irving S. Predictors of seasonal influenza vaccination during pregnancy. Obstet Gynecol. 2013;121: 741-9. https://doi.org/10.1097/AOG.0b013e3182878a5a.

49. Jiménez-García R, Hernandez-Barrera V, Rodríguez-Rieiro C, Carrasco Garrido P, López de Andres A, Jimenez-Trujillo I, et al. Comparison of self-report influenza vaccination coverage with data from a population based computerized vaccination registry and factors associated with discordance. vaccine. 2014;32:4386-92. https://doi.org/10.1016/j.vaccine.2014.06.074.

\section{Publisher's Note}

Springer Nature remains neutral with regard to jurisdictional claims in published maps and institutional affiliations.
Ready to submit your research? Choose BMC and benefit from:

- fast, convenient online submission

- thorough peer review by experienced researchers in your field

- rapid publication on acceptance

- support for research data, including large and complex data types

- gold Open Access which fosters wider collaboration and increased citations

- maximum visibility for your research: over $100 \mathrm{M}$ website views per year

At $\mathrm{BMC}$, research is always in progress.

Learn more biomedcentral.com/submissions 